\title{
Effect of alkali on alkali-surfactant flooding in an Upper Assam oil field
}

\author{
Kalpajit Hazarika ${ }^{1}$ S Subrata Borgohain Gogoi ${ }^{2}$
}

Received: 21 June 2019 / Accepted: 26 October 2019 / Published online: 4 November 2019

(c) The Author(s) 2019

\begin{abstract}
The effect of alkali on immiscible alkali-surfactant (AS) flooding is studied by injecting surfactant individually and surfactant along with alkali. First, reservoir core samples were characterized with the help of X-ray diffraction (XRD), scanning electron microscope (SEM) and thin slide analysis. Based on the clay content of the reservoir, surfactant was selected. Second, AS formulations were designed through dynamic interfacial tension (IFT) and wettability alteration analysis. Third, adsorption of surfactant on porous media was studied with or without alkali to find out the amount of surfactant adsorbed along with the isotherm mechanism. Fourth, core flooding experiments were conducted to find out the recovery efficiency after secondary brine flooding. XRD, SEM and thin slide analysis showed the presence of kaolinite, smectite, illite, silica, quartz in the rock sample. Based on the clay types, sodium dodecyl sulfate (SDS) was selected as surfactant for this study. Ultra-low dynamic IFT in the range of $10^{-3}$ was observed with SDS. Addition of alkali further reduced the IFT of the system. Initially, wettability of the reservoir under study was toward water wet, but during AS flooding it was altered to strongly water wet. Adsorption of surfactant on the porous media was reduced by the application of alkali. During secondary brine flooding, maximum recovery was found to be $49 \%$ of Initial Oil in Place. Another $14 \%$ of residual oil after secondary flooding was achieved by AS flooding.
\end{abstract}

Keywords Immiscible $\cdot$ Wettability $\cdot$ Formulation $\cdot$ Permeability $\cdot$ Porosity $\cdot$ Adsorption $\cdot$ Efficiency

\section{Introduction}

The continuous and systematic research on chemical enhanced oil recovery (EOR) started from 1980s. This era started with the research on different alkali-surfactant-polymer (ASP) process and their mechanism by Reed and Healy, Pope and Hirasaki (Healy and Reed 1977; Hirasaki 1981; Pope et al. 1978; Pope 1980). But the effect of IFT on displacement efficiency of water flooding was first put forward by Uren and Fahry (1927). However, due to the limitation of technology, this idea was not implemented at that time. Wagner and Leach studied the effect of IFT on displacement efficiency and proved that to improve the efficiency IFT value should be less than $0.07 \mathrm{mN} / \mathrm{m}$, and if the IFT decreases further, the displacement efficiency can be

Kalpajit Hazarika

Kalpajecm44@gmail.com

Presidency University, Bangalore, India

2 Dibrugarh University, Dibrugarh, Assam, India significantly increased (Wagner and Leach 1966). Reed and Healy pointed out that residual oil saturation will approach zero if IFT between surfactant slug and oil decreases to the range of $10^{-3} \mathrm{mN} / \mathrm{m}$ (Healy and Reed 1977). Different researchers have studied the effect of alkali on IFT, alteration of wettability, rheology and flow of chemical slug through the porous media, dynamic IFT, phase behavior analysis of chemical EOR process, and effect of salinity on recovery efficiency was studied in detail with the help of coreflood experiments (Nasr-El-Din and Taylor 1993, 1998; Hawkins et al. 1994; Nasr-El-Din 1992; Torrealba and Johns 2017; Torrealba et al. 2018a, b).

Upper Assam Basin is a good candidate reservoir for implementation of chemical EOR (Gogoi and Kakoty 2017). Earlier researchers identified BL as an efficient surfactant for Upper Assam Basin which is a waste product of paper mill, although much reduction in IFT was not observed (Gogoi 2010, 2014; Gogoi and Das 2012; Gogoi and Gogoi 2005). Gogoi (2011) studied alkali-surfactant (AS) flooding with SLS as surfactant and $\mathrm{NaOH}$ as alkali in oil fields of Upper Assam; she studied the phenomenon of adsorption and 
desorption of surfactants in the porous media (Sarmah et al. 2017; Gogoi 2011). Das and Gogoi (2015a, b) also observed that surfactant in the form of micelar can reduce the IFT between the oleic and aqueous phase to $10^{-3} \mathrm{mN} / \mathrm{m}$, thus leading to the EOR (Das and Gogoi 2015a, b). Initial studies on SDS has done by Hazarika et al. (2018), he worked on anionic surfactant for Upper Assam Basin, and SDS was found to be efficient (Hazarika et al. 2018; Hazarika and Gogoi 2014).

\section{Experiment}

\section{Materials and methods}

The list of material used in this study is tabulated in Table 1.

\section{Reservoir description}

Early history of oil and gas in Upper Assam Basin dates back to the discovery of crude oil in Naharpung, Assam in 1866 (Boruah 2014). The oil field was discovered in the late 1960s, and commercial production initially commenced from 1974. Since then the Upper Assam Basin has been producing crude oil from the oil reservoirs and today it is in the late stage of depletion by way of primary and secondary recovery processes (Gogoi 2007). Therefore, the need of the hour is the call for EOR. Several studies and verbal discussions with the oil and gas exploration sectors of Assam confirm that $30 \%$ oil crude oil is extracted by way of primary and secondary recovery processes, and the rest $70 \%$ is left for EOR. Oil is mainly produce from Tipam Sand, Barail Coal Sand and Barail Main Sand. The sediments are mainly sandstone mixed with clays and shales. The clay types present were smectite, kaolinite and illite with a dominance of smectite and kaolinite, confirming to the swelling and disintegration of clays, respectively. The reservoir pressure initially was around $3400 \mathrm{psi}$ at a depth of around 3136-3439 meters, and the reservoir temperature is less than $90^{\circ} \mathrm{C}$. The

Table 1 List of material

\begin{tabular}{|c|c|c|}
\hline S. no. & Material & Source \\
\hline 1 & Core sample & $\begin{array}{l}\text { Collected from Upper Assam } \\
\text { Basin }\end{array}$ \\
\hline 2 & Crude oil sample & $\begin{array}{l}\text { Collected from Upper Assam } \\
\text { Basin }\end{array}$ \\
\hline 3 & $\begin{array}{l}\text { Sodium dodecyl sulfate } \\
\text { (SDS) }\end{array}$ & Sigma-Aldrich Co., Mumbai \\
\hline 4 & Sodium hydroxide $(\mathrm{NaOH})$ & $\begin{array}{l}\text { RANKEM, RFCL Ltd., New } \\
\text { Delhi }\end{array}$ \\
\hline 5 & Sodium carbonate $\left(\mathrm{Na}_{2} \mathrm{CO}_{3}\right)$ & Lobal Chemie, Mumbai \\
\hline 6 & Liquid paraffin (light) & Fisher Scientific, New Delhi \\
\hline
\end{tabular}

porosity of the reservoir is approximately in the range of 23-29\% and absolute permeability is in between 50-94 mD. The crude oil was medium gravity (API gravity $34^{\circ}$ ) with acid number $<1.7 \mathrm{mg}$ of KOH/gm, (Phukan et al. 2018).

\section{Core samples}

The conventional core samples of the porous media were collected from Upper Assam oil reservoir from a depth of 3136-3439 m. The core samples were cut into plugs of 1.5 inch diameter, smoothened, end faced, cleaned by liquid-liquid extraction in Soxhlet apparatus by taking mixture of toluene and xylene in the ratio of 1:1 and ultrasonically and then dried in humidifier control oven. Effective porosities of the samples were measured in TPI 219 Teaching Helium Porosimeter and found to be around $25 \%$. The average absolute permeability of the reservoir rock was around $70 \mathrm{md}$. XRD, SEM and thin slide analysis of the rock sample were done to find out the dominant clay present in the reservoir. It was found in both the XRD and SEM image (Figs. 1 and 2 ) that the dominant clay is smectite and kaolinite, which are anionic in nature. Therefore, the reservoir under study was anionic reservoir. On the other hand, the presence of quartz and feldspar was observed in thin slide analysis (Fig. 3). Due to quartz over growth, there will be reduction in volume of the pores and the throats; due to weathering of quartz, there will be accumulation of the weathered quartz particle in the reservoir fluids. If the particle size of the weathered particles is such that it is in motion with the reservoir fluids specially the displacing fluid then the viscosity of the displacing fluid is increased, thereby, decreasing the mobility ratio and enhancing the macroscopic sweep efficiency of the reservoir. If the particle size of the weathered quartz is larger enough to precipitate in the reservoir, it will be obstruction in the flow of fluids through the porous media, leading to the reduction in permeability and porosity of the porous media.

\section{Experimental procedure}

\section{Equilibrium IFT measurements}

IFT experiments were conducted in spinning drop tensiometer. The principle of spinning drop tensiometer is to determine the IFT between the lighter and the heavier phase (Gogoi 2011). The crude oil was injected by a needle in the aqueous phase of the capillary tube of Grace M6500. Due to the density difference, the oil drops is in the middle of capillary tube in horizontal position. In spinning drop tensiometer, the rotation takes place around " $x$ " axis. The drop shape exhibits symmetry around axis " $x$ ". The centrifugal acceleration is $\omega^{2} y(\omega$ is the rotational velocity), and it increases with the distance from the axis and is such that the natural gravity effect is negligible. 


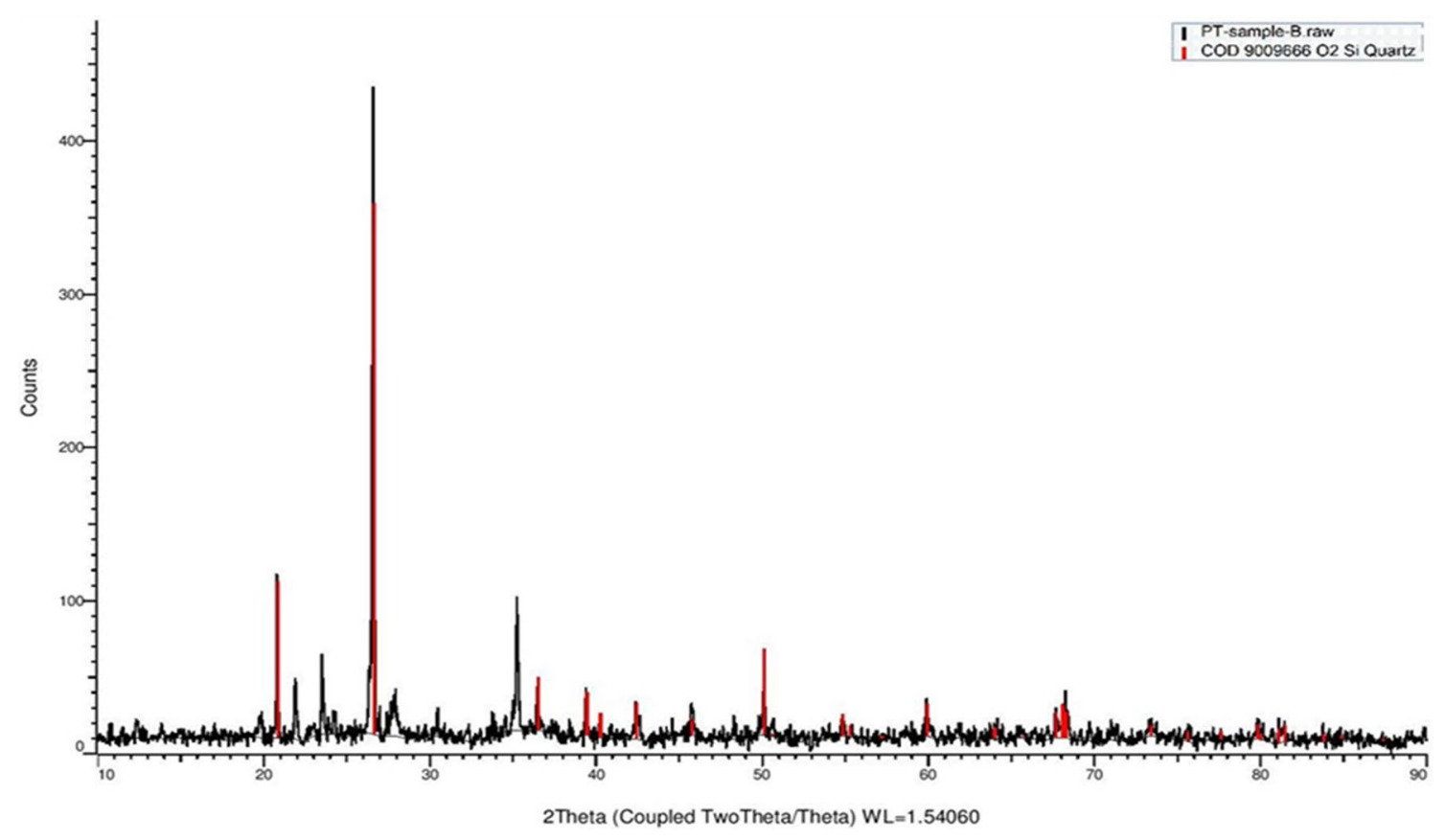

Fig. 1 XRD diffraction pattern of the powder reservoir rock sample

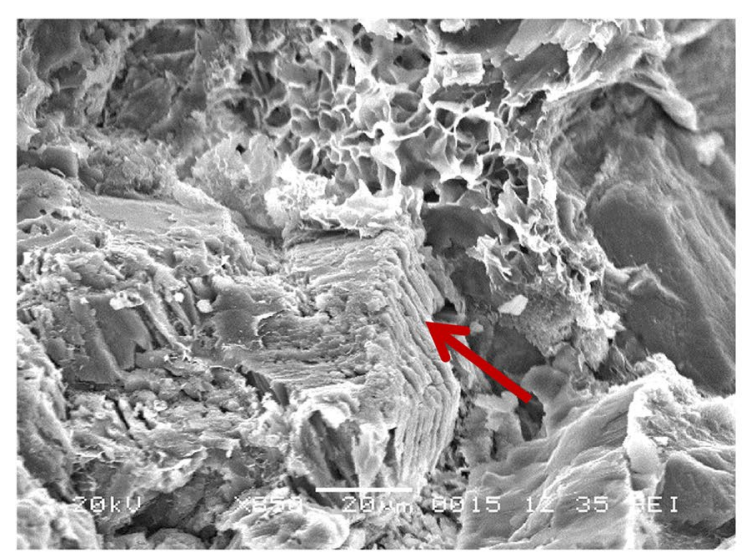

Kaolinite

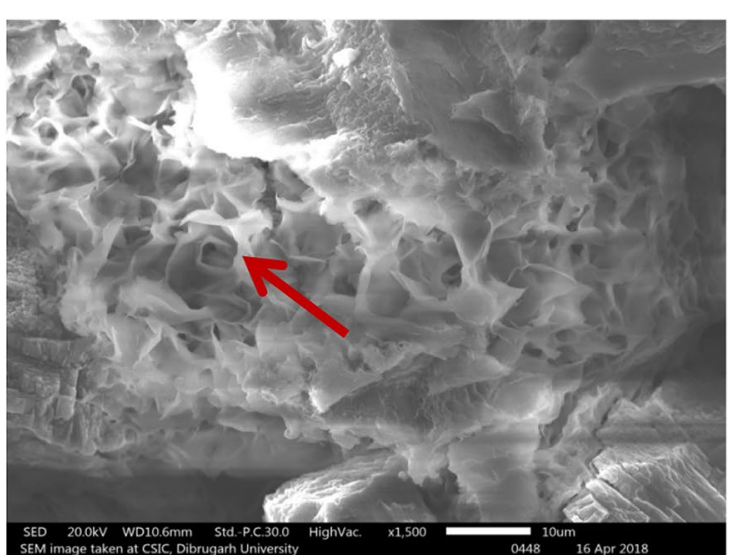

Smectite

Fig. 2 SEM image of the rock sample

Hence, the influence of the density difference between the two fluids increases with the distance from the axis and produces a pull of the interface toward the axis. These results in the elongation of the drop along the " $x$ " axis, which is opposed by the interfacial tension that tends to minimize the surface area, i.e., to make the drop shape more spherical (Das and Gogoi 2015a, b).

The profile of the oil drops with angular velocity $\omega$ about the $X$ axis (Fig. 4). Since the acceleration toward the axis of any point $X Y$, hydrostatic pressure $(P)$ corresponding to $h \rho g$ in the gravitational field

Pressure, $\quad P=\frac{\Delta \rho \times \omega^{2} y^{2}}{2}, \quad$ assuming $\} g^{\prime}$ is negligible

If the radius of curvature of the drop at the axis is ' $b$ ', the $\Delta \rho$ is the density difference at interface due to IFT

$\Delta \rho=\frac{\gamma}{2 b}$ 


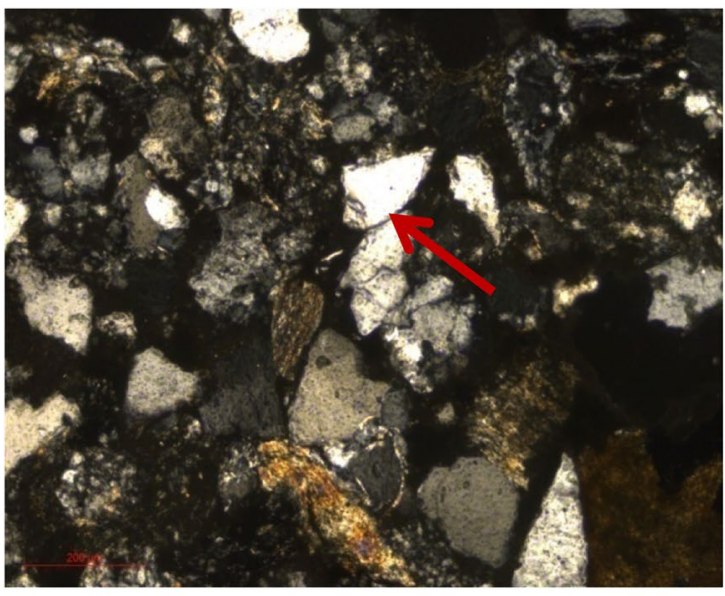

Line contact in quartz grain

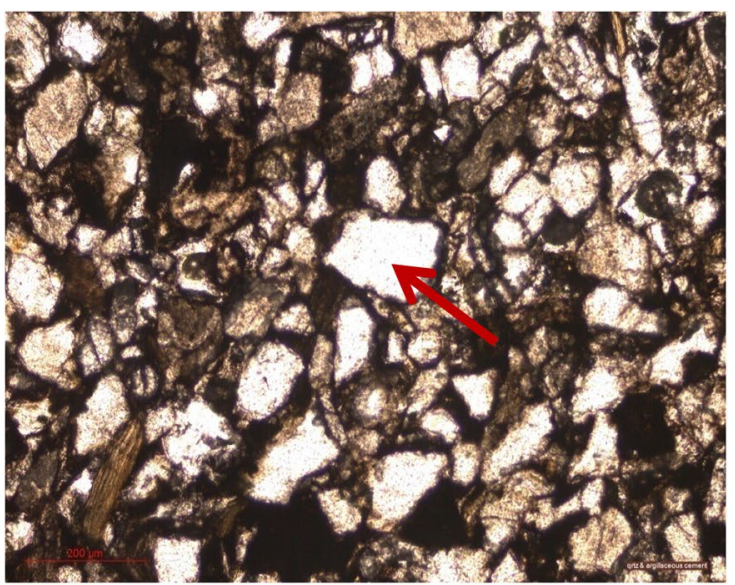

Presence of Quartz

Fig. 3 Thin section images of sandstone showing the presence of Line contact in quartz

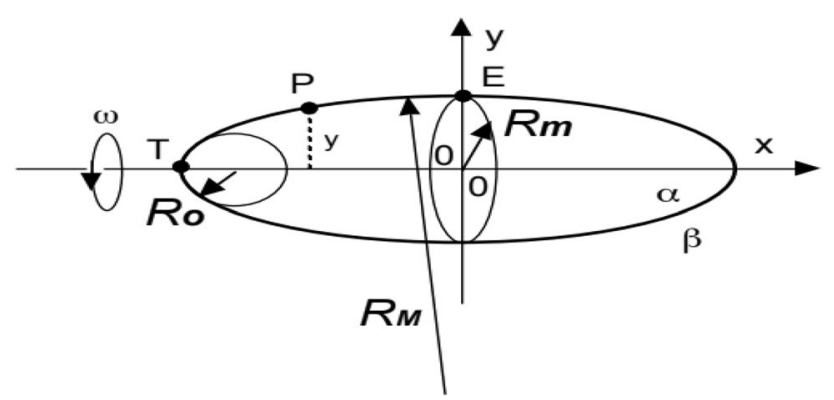

Fig. 4 Geometry of a spinning drops of denser liquid $\alpha$ in less dense liquid $\beta$

The Laplace equation for $\Delta \rho$ at point $x y$ on the surface

$\Delta \rho=\gamma\left(\frac{d \sin \theta}{d y}+\frac{\sin \theta}{y}\right)=\frac{\gamma}{2 b}-\frac{\Delta \rho \omega^{2} y^{2}}{2}$

which can be expressed in dimensionless form

$\frac{\mathrm{d} \sin \theta}{\mathrm{d} Y}+\frac{\sin \theta}{Y}=2-\alpha Y^{2}$

where $Y=\frac{y}{b}$ and $\alpha=\Delta \rho \omega^{2} b^{3}$. We have

$\Delta \rho=\frac{2 \gamma}{b}-\frac{\Delta \rho \omega^{2} y^{2}}{2}$

$\frac{2 \gamma}{b}=\Delta \rho+\frac{\Delta \rho \omega^{2} y^{2}}{2} \quad$ or $\quad \frac{\gamma}{b}=\frac{\Delta \rho}{2}+\frac{\Delta \rho \omega^{2} y^{2}}{4}$

If $b=y$ and neglecting pressure term we have

$\gamma=\frac{\Delta \rho \omega^{2} y^{3}}{4}$
This is the Vonnegut's formulawhere $\gamma=$ IFT in $(\mathrm{N} / \mathrm{m})$, $y=$ mean radius in $(\mathrm{m}), \Delta \rho=$ density difference in $\left(\mathrm{Kg} / \mathrm{m}^{3}\right)$, $\omega=$ angular velocity in $(\mathrm{rad} / \mathrm{s})$.

If the measured diameter differs from the true diameter by the magnification factor for water (1.33) and measured diameter is used rather than the radius, then

$\gamma=\frac{1}{4} \Delta \rho \frac{(2 \pi \theta)^{2}}{60^{2}} \times \frac{D^{3}}{(2 \times 10 \times 1.33)^{3}}=1.455 \times 10^{-7} \times \Delta \rho \theta^{2} D^{3}$

where $D=$ diameter in $\mathrm{mm}$ read directly from instrument, $\theta=$ rotation in rpm read directly from instrument.

This formula has been shown to be valid for $\frac{L}{D}>4$, if the length of the drop exceeds 4 times its diameter. Since the centrifugal acceleration is not constant along the elongated drop, therefore, the radius at the tip is not equal to that in center (Phukan et al. 2018; Hazarika et al. 2018).

\section{Wettability}

Wettability calculation was done by relative permeability curves obtained from core flood analysis. The process of drainage was started by flooding the core plug with light paraffin oil. Relative permeability of oil with respect to brine will be measured till initial water saturation $\left(S_{\mathrm{wi}}\right)$ (Laishun 2000; Elraies and Tan 2012). The process of imbibitions was started by flooding the core plug with $3000 \mathrm{ppm}$ brine. The effective permeability of oil was determined till the breakthrough of brine was observed by applying the Darcy's law. Relative permeability of brine with respect to oil will be measured till residual oil saturation $\left(S_{\text {or }}\right)$. 


\section{Contact angle}

Contact angle of samples was measured in KRUSS DSA100 instrument. From the contact angle values, wettability was determined (Erincik et al. 2018). Contact angle is an important criterion for alkali flooding. For chemical EOR process, the reservoir rock should be water wet; otherwise it should be altered from oil wet to water wet by alkali flooding (Fan et al. 2018; Vik et al. 2018). Wettability depends on contact angle. The wettability obtained from DSA 100 was validated with the relative permeability graph obtained from JBN method. In relative permeability curve if the crossover point between non-wetting phase and wetting phase is $50 \%$ of water saturation $\left(S_{\mathrm{w}}\right)$, then the rock is said to be water wet; otherwise it is oil wet (Fan et al. 2018; Berg 2009). Alkali has a strong role over the alteration of wettability. It changes the wettability from oil wet to water wet which is desirable for ASP flooding (Hunter 1981, Shukla and Rehage 2008). Experiments were done to find out the contact angle of different crude oil samples saturate with brine, surfactant and surfactant with alkali.

The core plug was polished to get a smooth surface and saturated in $3000 \mathrm{ppm}$ brine solution under vacuum for at least $3 \mathrm{~h}$. The core plug was then inserted in a beaker containing crude oil and centrifuged it for $30 \mathrm{~min}$. To remove the surface oil, it was inserted in a beaker containing toluene. The core plug was placed in the core holder and one drop of crude oil was injected by the needle from the bottom; the photograph was taken by the camera fitted with the instrument. The angle between the tangent drawn on the oil drop and the rock surface was the contact angle. Same experiment was repeated by saturating the core plug in surfactant (SDS) and surfactant + alkali $\left(\mathrm{SDS}+\mathrm{Na}_{2} \mathrm{CO}_{3}\right)$ at $80{ }^{\circ} \mathrm{C}$.

\section{Adsorption tests}

The absorbance value was obtained from the spectrophotometer (Cal et al. 1994). From the absorbance value, the concentration was determined from the calibration curve. The amount adsorbed was calculated by following equation

$Q_{e}=\left(C_{0}-C_{e}\right) \frac{V}{m}$

where $Q_{e}=$ amount adsorbed in $\mu \mathrm{g} / \mathrm{g}, C_{\mathrm{o}}=$ concentration before adsorption $(\mu \mathrm{g} / \mathrm{mL}), C_{e}=$ concentration after adsorption from calibration curve $(\mu \mathrm{g} / \mathrm{mL}), V=$ solution volume $(\mathrm{mL}), m=$ mass of adsorbent $(\mathrm{g})$.

The absorbance values for each unknown sample were recorded and these absorbance values were interpreted with the calibration graph to determine the concentration of unknown sample (Schramm 2000; Laura et al. 2000).

\section{Core flooding experiments}

After cleaning, the core sample was first saturated with $3000 \mathrm{ppm}$ brine and it was placed in the core holder of core flooding instrument. Drainage process was started with paraffin oil up to the first drop of oil recovered from the core sample. Imbibition or secondary brine flooding was continued from oil saturation $\left(S_{\mathrm{o}}\right)$ till $S_{\text {or }}$ Residual oil can be recovered by ASP EOR process. Microscopic displacement efficiency $\left(E_{d}\right)$ was calculated from the results of core flooding experiments to determine the efficiency of alkali (A), surfactant (S) and AS flooding by using the following equation.

$$
\begin{aligned}
& E_{d}=\frac{S_{\mathrm{o}}-S_{\mathrm{or}}}{S_{\mathrm{o}}} \\
& E_{d}=1-\frac{S_{\mathrm{or}}}{S_{\mathrm{o}}}
\end{aligned}
$$

\section{Results and discussion}

\section{IFT}

IFT experiments were conducted to find the critical micelle concentration (CMC) value of SDS and the effect of $\mathrm{Na}_{2} \mathrm{CO}_{3}$ on the IFT (Hazarika et al. 2018). The result shows the experimental findings of IFT in between aqueous phase containing SDS and SDS $+\mathrm{Na}_{2} \mathrm{CO}_{3}$ and oleic phase containing $\mathrm{NH}$ crude. It is shown that the dynamic IFT is minimum in case of the formulated slug comprising of $0.4 \mathrm{vol} . \%$ of $0.1 \mathrm{M}$ SDS (Fig. 5). The effect of $\mathrm{Na}_{2} \mathrm{CO}_{3}$ on IFT was studied keeping the surfactant concentration constant ( $0.4 \mathrm{vol} . \%$ of $0.1 \mathrm{M} \mathrm{SDS}$ ). Addition of $\mathrm{Na}_{2} \mathrm{CO}_{3}$ further reduced the IFT in between the aqueous and oleic phase as shown in Fig. 6, the lowest IFT was achieved at 0.85 wt. $\%$ of $\mathrm{Na}_{2} \mathrm{CO}_{3}$

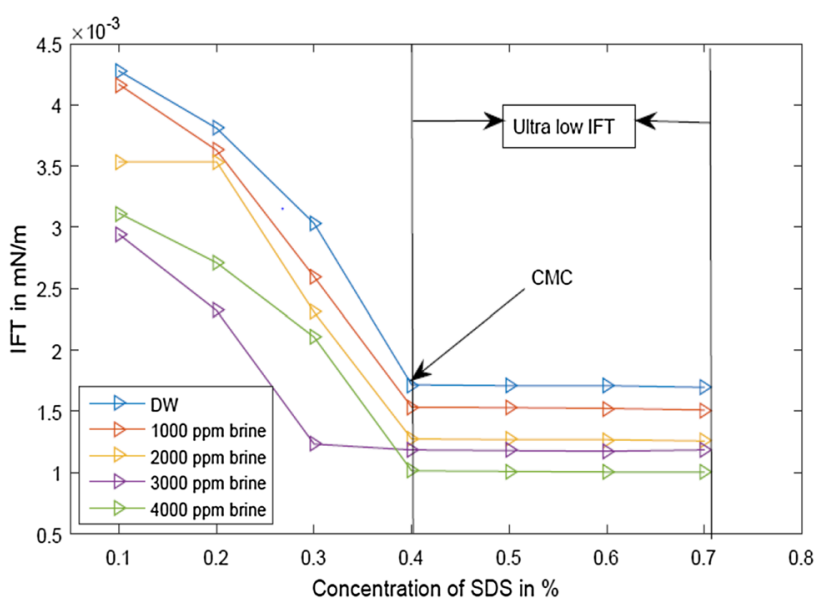

Fig. 5 IFT between NH crude and SDS 


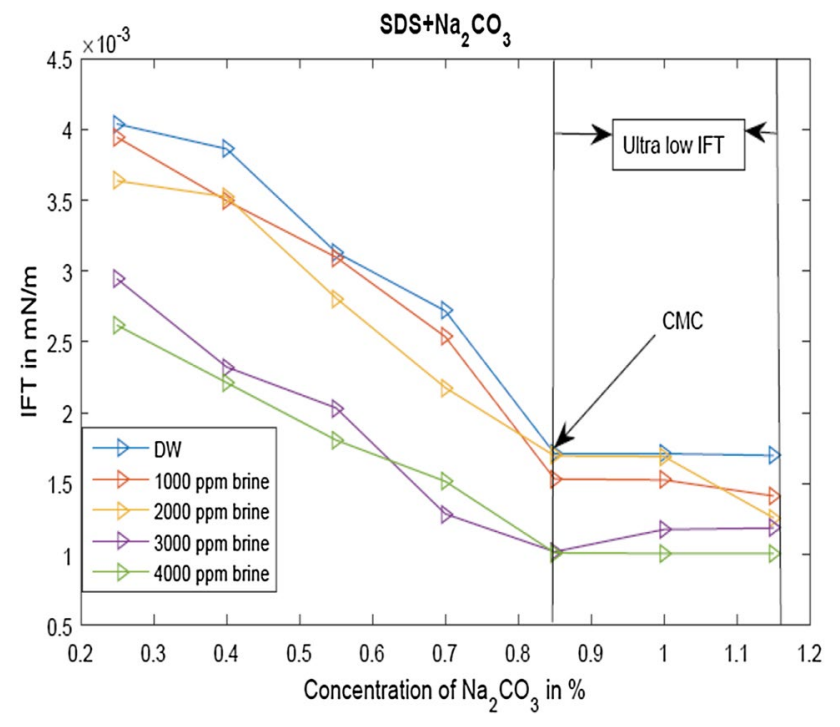

Fig. 6 IFT between $\mathrm{NH}$ crude and $\mathrm{SDS}+\mathrm{Na}_{2} \mathrm{CO}_{3}$

(Fig. 6). Therefore, the best slug formulated for AS-EOR was $0.4 \mathrm{vol} . \%$ of $0.1 \mathrm{M} \mathrm{SDS}+0.85 \mathrm{wt} \%$ of $\mathrm{Na}_{2} \mathrm{CO}_{3}$. Ultralow IFT value in the range of $10^{-3} \mathrm{mN} / \mathrm{m}$ was achieved by this slug. Salinity plays an important role on chemical EOR process (Soo and Radke 1984). Increasing the salinity of the EOR slug will further reduce the IFT values. The optimum salinity of the slug can be found out from phase behavior analysis. At low salinity type I microemulsion is formed, while at high salinity type II microemulsion is formed. The salinity at which type III microemulsion is formed is the optimum salinity for that reservoir. The optimum salinity of the reservoir under study was found to be $3000 \mathrm{ppm}$ from Fig. 7. Initially at low slug salinity, the color of the aqueous phase was dark, while at $3000 \mathrm{ppm}$ the color changed to slightly light. On the other hand, the salinity of the reservoir under study was in the range of $3000-4000 \mathrm{ppm}$. So the optimum salinity is compatible with the reservoir fluid salinity.

Hydrophile-lipophile balance (HLB) value is one of the most useful parameter for selecting surfactant in EOR. The solubility of surfactant whether it is soluble in aqueous or oleic phase will be determined by HLB value (Housaindokht and Nakhaei 2012). The higher the HLB value is, the more water soluble the surfactant and the reverse is true for oil soluble. The normal range of HLB value is from 0 to 20 (Aveyard et al. 1986) but in some cases due to the high solubility of surfactant in water this value goes to 40 (Berg 2009). High value of HLB favors the formation of o/w emulsions while low value is for w/o emulsions. Further studies have shown that the HLB for SDS is 40 (Kim and Allee 2001). The HLB values are in agreement with theory. The type of emulsion formed by the surfactant can be estimated by Bancroft's rule, which is based on HLB: "When an interfacial active agent is present along with two immiscible liquids, then after agitation the liquid that is the better solvent appears as the continuous phase" (Marszall 1977). o/w emulsion is more suitable than w/o emulsion in chemical EOR technique because in case of w/o emulsion there is loss of surfactant and also it changes the system viscosity (Alagic and Skauge 2010). Critical packing parameter (CPP) is a factor that effects the chemical EOR process. It determines the shape of the surfactant aggregate structure whether it is spherical or rod in the emulsions. CPP $<1$ describes the
Fig. 7 Phase behavior analysis of crude with SDS

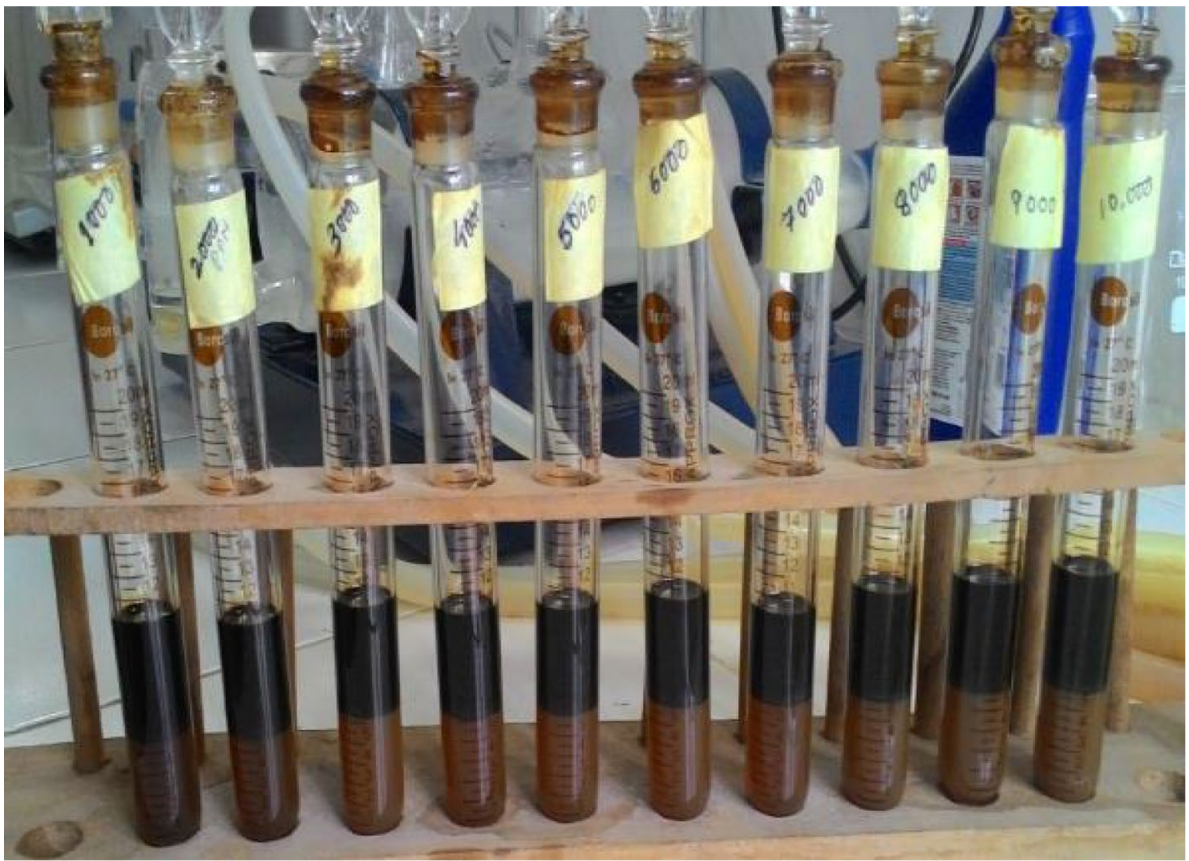


formation of spherical shape aggregation. The value of the CPP has been found by Wang and Mittal, for SDS it is $1 / 3$. Ultra-low IFT was achieved due to the formation of spherical shape aggregation. Addition of $\mathrm{Na}_{2} \mathrm{CO}_{3}$ further reduced the IFT values. This is because, on addition of $\mathrm{Na}_{2} \mathrm{CO}_{3}$, the capability of reduction in IFT by SDS was increased due to the less adsorption of SDS on the porous media. Alkali can alter the adsorption mechanism from multilayer adsorption to monolayer adsorption (Hazarika et al. 2018). Further alkali can produce in situ surfactant with crude oil which will further reduce the IFT (Aveyard et al. 1986). $\mathrm{Na}_{2} \mathrm{CO}_{3}$ solutions are less corrosive to sandstone. $\mathrm{Na}_{2} \mathrm{CO}_{3}$ buffering action can reduce alkali retention in the rock formation. Low tensions required for EOR by alkaline flooding can be achieved with alkaline solutions at $\mathrm{pH}<11$ (Sheng 2010).

\section{Solubilization of surfactant}

Solubilization parameter $V_{\mathrm{o}} / V_{\mathrm{s}}$ is the ratio of volume of oil to the volume of surfactant while $V_{\mathrm{w}} / V_{\mathrm{s}}$ is the water to surfactant in the emulsion (Torrealba and Johns 2017). $V_{\mathrm{o}} / V_{\mathrm{s}}$ increases with salinity while $V_{\mathrm{w}} / V_{\mathrm{s}}$ decreases with increase in salinity. The crossover point is the optimum salinity of the slug and at this salinity the IFT is lowest (Healy and Reed 1974, 1977; Healy et al. 1976). The optimum salinity for this case is $3000 \mathrm{ppm}$ as in Fig. 8. This is in line with the result found from Fig. 7. In 1979, Huh established a relationship between the solubilization parameter and IFT. According to this relationship, IFT varies inversely to the square of solubilization parameter (Huh 1979).

$\sigma=\frac{C}{\left(\frac{V_{i}}{V_{\mathrm{s}}}\right)^{2}}$

w h e r e $\quad \sigma=I F T, \quad V_{i}=$ volume of oil or water, $V_{\mathrm{s}}=$ volume of surfactant, $V_{0}=$ volume of oil, $V_{\mathrm{w}}=$ volume water.

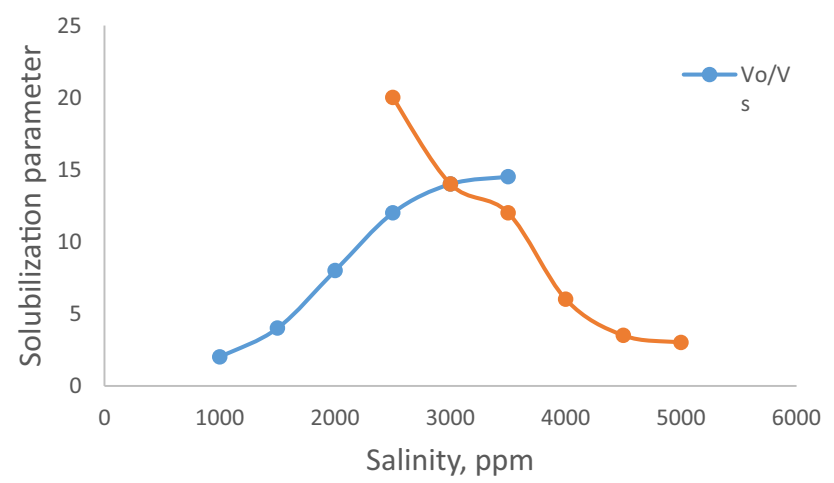

Fig. 8 Salinity versus solubilization parameter
$C$ is constant, and for most of the crude and microemulsion this value is equal to 0.3. IFT experimental results substantiate this relation (Healy and Reed 1977).

\section{Wettability}

The wettability of crude oil samples with the porous media was found during the imbibition process from the relative permeability curves (Figs. 9 and 10). The wettability of the porous media was determined as per Table 2 (Craig 1971).

Wettability are calculated as per Table 2 and reported in Table 3. Accordingly, the two core samples were found to be water wet (WW) when determining the water saturations

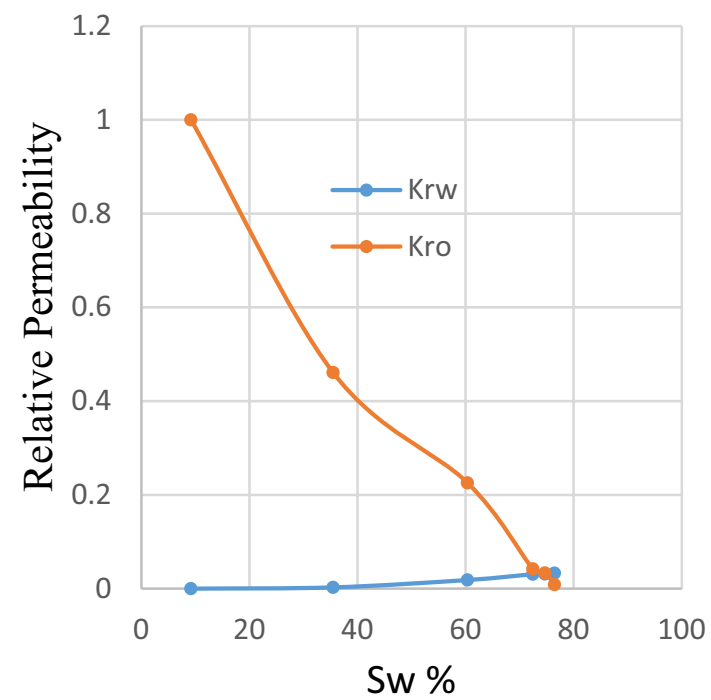

Fig. 9 Relative permeability of NHP-1

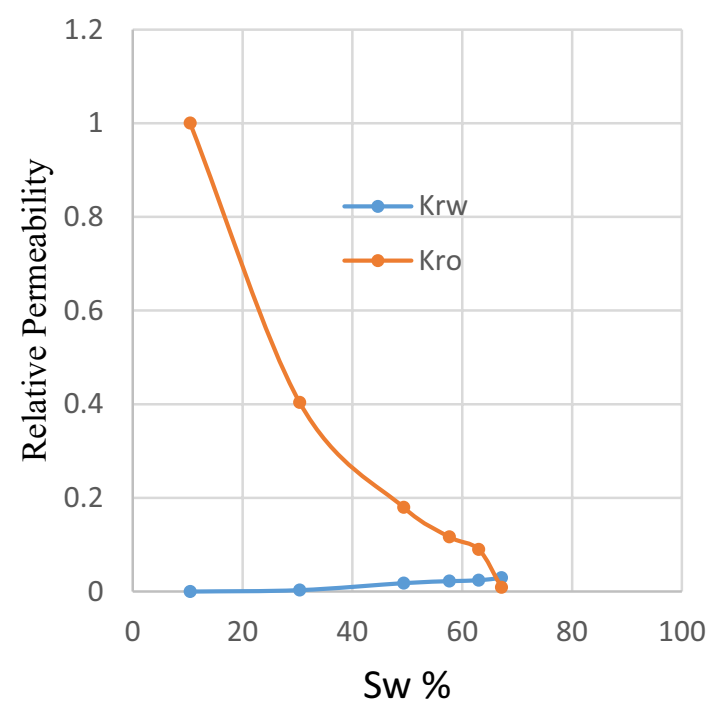

Fig. 10 Relative permeability of NHP-2 
Table 2 Rules of thumb for wettability inference from oilwater relative permeabilities during imbibition process by Craig (1971)

Table 3 Wettability from relative permeability of oil with respect to water, during the imbibition process

\begin{tabular}{llll}
\hline S. no. & Criterion & Water wet $(\%)$ & Oil wet $(\%)$ \\
\hline 1 & End point relative permeability to water at $S_{\text {or }}$ & $<30$ & $<50$ \\
2 & Water saturation at crossover point & $>50$ & $<50$ \\
3 & Initial water saturation $\left(S_{\text {wi }}\right)$ & $>25$ & $<15$ \\
\hline
\end{tabular}

\begin{tabular}{llllcll}
\hline S. no. & Porous media & Crude oil & $\begin{array}{l}\text { Crossover point } \\
\text { in } \% \text { of } S_{\text {wi }}\end{array}$ & $S_{\text {wi }}$ & $K_{\text {rw }}$ at $S_{\text {or }}$ & Wettability \\
\hline 3 & NHP-1 & NH-1 & 72 & 9.8 & 28 & WW/MW/SW \\
2 & NHP-2 & NH-2 & 68 & 10.45 & 33 & WW/MW/SW \\
\hline
\end{tabular}

\begin{tabular}{llll}
\hline Sample & $\begin{array}{l}\theta^{\circ} \text { between } \mathrm{CO} \text { and } \\
3000 \mathrm{ppm} \text { brine }\end{array}$ & $\begin{array}{l}\theta^{\circ} \text { Between } \mathrm{CO} \text { and } \\
\mathrm{SDS}+3000 \mathrm{ppm} \text { brine }\end{array}$ & $\begin{array}{l}\theta^{\circ} \text { between } \mathrm{CO} \text { and } \\
\left(\mathrm{SDS}+\mathrm{NaCO}_{3}\right)+3000 \mathrm{ppm} \\
\text { brine }\end{array}$ \\
\hline NHC-1 & 76 & 94 & 124 \\
NHC-2 & 82 & 98 & 129 \\
\hline
\end{tabular}

Table 4 Contact angle of core samples

\section{Adsorption}

It was observed that adsorption was more when SDS was the adsorbate as in Fig. 11. Results indicate that addition of alkali reduces the adsorption of anionic surfactant. This is in line with the earlier researchers Samanta et al. (2012). This shows that alkali plays a major role in adsorption of SDS in porous media. The reservoir under study is anionic in nature as it contains kaolinite and smectite (Figs. 1, 2 and 3). Kaolinite is a well-defined aluminosilicate with a 1:1 layer unit structure consisting of a single silica tetrahedral sheet and a single alumina octahedral sheet. The ionic charge of kaolinite is zero if the $\mathrm{pH}$ range (PZC) value is 4.5-5.0. Kaolinite disintegrates during the secondary brine and chemical flooding and lead to yield a new gibbsite $\left(\mathrm{Al}(\mathrm{OH})_{3}\right)$ phase, which PZC is in the range of 8.5-9.1 (Parks and Bruyn 1962). The newly form Gibbsite surface has some positive charge below pH 9.1. The negatively charged surfactant can be attracted or adsorbed by these positive charges. Addition of alkali will increase the $\mathrm{pH}$ of the chemical slug, which will decrease the positive charge on the surface. Hence, the adsorption of surfactant will be reduced. Another function of alkali is that it can consume multivalent cations in the solution which would precipitate surfactant molecules.

Multilayer adsorption may take place when the slug contains only surfactant, because at low $\mathrm{pH}$ the porous media has more positively charged site. Since addition of alkali will reduce these positively charged site, hence the adsorption may be monolayer. In monolayer adsorption, only a single 
Table 5 Brine flooding

\begin{tabular}{lllll}
\hline Core sample & $\begin{array}{l}\text { Initial oil } \\
\text { saturation } \\
\left(S_{\mathrm{oi}}\right)\end{array}$ & $\begin{array}{l}\text { Secondary } \\
\text { recovery }(\%)\end{array}$ & $S_{\mathrm{or}}$ & $E_{\mathrm{d}}=1-\frac{S_{\mathrm{or}}}{S_{\mathrm{o}}}(\%)$ \\
\hline NHP-1 & 90.8 & 47.1 & 43.7 & 48.13 \\
NHP-2 & 89.16 & 49.54 & 39.62 & 44.44 \\
\hline
\end{tabular}

Table 6 Alkali flooding

\begin{tabular}{llllll}
\hline Core sample & $S_{\mathrm{o}}$ & Slug & Recovery $(\%)$ & $S_{\text {or }}$ & $\begin{array}{l}E_{\mathrm{d}}=1-\frac{S_{\text {or }}}{S_{\mathrm{o}}} \\
(\%)\end{array}$ \\
\hline NHP-1 & 43.7 & $\mathrm{Na}_{2} \mathrm{CO}_{3}$ & 3.8 & 40.25 & 7.90 \\
NHP-2 & 39.62 & $\mathrm{Na}_{2} \mathrm{CO}_{3}$ & 4.4 & 35.70 & 9.90 \\
\hline
\end{tabular}

Table 7 Surfactant flooding (SDS)

\begin{tabular}{lllll}
\hline Core sample & $S_{\mathrm{o}}$ & Recovery $(\%)$ & $S_{\text {or }}$ & $E_{\mathrm{d}}=1-\frac{S_{\text {or }}}{S_{\mathrm{o}}}(\%)$ \\
\hline NHP-1 & 40.25 & 6.6 & 34.26 & 14.89 \\
NHP-2 & 35.70 & 7.1 & 29.37 & 17.73 \\
\hline
\end{tabular}

Table 8 AS flooding

\begin{tabular}{llllll}
\hline $\begin{array}{l}\text { Core } \\
\text { sample }\end{array}$ & $S_{\mathrm{o}}$ & Slug & Recovery $(\%)$ & $S_{\text {or }}$ & $E_{\mathrm{d}}=1-\frac{S_{\text {or }}}{S_{\mathrm{o}}}(\%)$ \\
\hline NHP-1 & 34.26 & $\mathrm{SDS}+\mathrm{Na}_{2} \mathrm{CO}_{3}$ & 4.3 & 30.35 & 11.35 \\
$\mathrm{NHP}-2$ & 29.37 & & 2.2 & 27.40 & 6.67 \\
\hline
\end{tabular}

layer of surfactant is adsorbed on to the surface of the porous media and moreover when a site is occupied by solute no further adsorption takes place (Fritz and Schlunder 1981; Hanna and Somasundaran 1977).

\section{Core flooding}

After drainage process, the initial oil saturation was almost $90 \%$ for both the samples. During secondary brine flooding, $47.1 \%$ of oil for NHP- 1 and $49.54 \%$ oil for NHP-2 were recovered as shown in Table 5. Remaining oil after secondary flooding $\mathrm{S}_{\text {or }}$ was the target for AS flooding.

The $S_{\text {or }}$ of Table 5 is the $S_{0}$ for alkali flooding. The recovery efficiency for alkali flooding was $3.8 \%$ and $4.4 \%$ for NHP-1 and NHP-2, respectively, as shown in Table 6. Similarly for surfactant flooding, the recovery was found to be $6.6 \%$ and $7.1 \%$, respectively, as in Table 7 . Finally, the formulated AS-EOR slug of 0.4 vol. $\%$ of $0.1 \mathrm{M}$ $\mathrm{SDS}+0.85 \mathrm{wt} \%$ of $\mathrm{Na}_{2} \mathrm{CO}_{3}$ was flooded and recovery was found to be $4.3 \%$ and $2.2 \%$, respectively, as in Table 8 . The $S_{\text {or }}$ for NHP-1 was decreased from 43.7 to $30.35 \%$ by applying A, S and AS slug, while for NHP-2 it was decreased from 39.62 to $27.40 \%$.

The effect of alkali does not only have an effect with regards to the charge of the head group of the surfactant, it also alters the aqueous phase' solubility. As concentration of salt increases, the solubility of surfactant in the aqueous phase decreases. As the solubility decreases, the surfactant starts accumulating at the interface instead of in the bulk. The salt concentration where the solubility of the surfactant is equal in both the oil and the water phase is where the surfactant has its highest affinity to the interface. The change in IFT is a function of salinity. An increasing salinity will increase the surfactants affinity to the interface, resulting in a higher concentration of monomers at the interface, and thus a lower IFT.

When a charged particle is present in a solution containing excess ions, those ions will orient themselves around the charged particle to electrostatically neutralize the particle. Closest to the particle, a layer consisting of only ions with opposite charge of the particle will accumulate. Further out from the charged particle, both ions of the same charge and the opposite charge will accumulate in a layer, larger than the inner one. These two layers are what is called the electrical double layer (EDL) (Berg 2009; Hunter 1981; Shukla and Rehage 2008). When two surfactant monomers with the same charge of the head group is present at an interface, their EDL will interact and repel each other, as the two monomers have the same charge. However, when salt is introduced to the system, positive and negative ions will interact with the double layer, decreasing the size of the EDL, and hence the repulsion between the two monomers (Brown et al. 2016). This is the reason why CMC, IFT as well as microscopic displacement efficiency decrease in a surfactant-containing system when alkali is introduced to the system.

\section{Conclusions}

The reservoir under study was anionic in nature as it has predominance of kaolinite and smectite clay. Therefore, anionic surfactant SDS was selected for this reservoir, because during adsorption phenomena anionic clay and anionic surfactant will repeal each other. Addition of alkali $\left(\mathrm{Na}_{2} \mathrm{CO}_{3}\right)$ further reduces the IFT between oleic and aqueous phase by the formation of in situ surfactant. Again it changes the wettability from less water wet to strong water wet. During adsorption phenomena, alkali reduces the adsorption of surfactant due to increase in $\mathrm{pH}$ of the slug and also reduces the reactive cationic sites. Thus, it increases the efficiency and capability of AS slug to recover more oil during AS EOR flooding. The residual oil saturation decreases from 48 to $30 \%$ due to the injection of chemical slug in the reservoir under study.

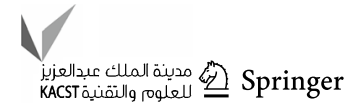


Acknowledgements Sincere thanks and gratitude are expressed by the authors to Oil India Ltd., for providing the reservoir cores samples and crude oils of the oil field of Upper Assam. Special thanks go to DST project no SB/S3/CE/057/2013 for financial support for this study.

Open Access This article is distributed under the terms of the Creative Commons Attribution 4.0 International License (http://creativeco mmons.org/licenses/by/4.0/), which permits unrestricted use, distribution, and reproduction in any medium, provided you give appropriate credit to the original author(s) and the source, provide a link to the Creative Commons license, and indicate if changes were made.

\section{References}

Alagic E, Skauge A (2010) A combined low salinity brine injection and surfactant flooding in mixed-wet sandstone cores. Energy Fuels 24:3551-3559

Aveyard R et al (1986) Interfacial tension minima in oil-surfactant systems: behaviour of alkane-aqueous $\mathrm{NaCl}$ systems containing Aerosol OT. J Chem Soc Faraday Trans I 82(1):125-142

Berg JC (2009) An introduction to interfaces and colloids: the bridge to nanoscience. World Scientific Publishing Co. Pte. Ltd., Singapore, $\mathrm{p} 804$

Boruah DM (2014) Polity and petroleum making of an oil industry in Assam, 1825-1980. PhD Thesis, Indian Institute of Technology, Guwahati

Brown MA, Goel A, Abbas Z (2016) Effect of electrolyte concentration on the stern layer thickness at a charged interface. Angew Chem Int Ed 55(11):3790-3794

Cal MP, Larson SM, Rood MJ (1994) Experimental and modeled results describing the adsorption of acetone and benzene onto activated carbon fibers. Environ Prog 13:26-30

Craig FF (1971) The reservoir engineering aspects of water flooding. In: SPE monograph 3. Richardson, TX

Das BM, Gogoi SB (2015a) Relating IFT with oil recovery with special reference to bhogpara porous media of upper Assam basin. $\mathbf{J}$ Petrol Eng Technol 5(1):1-8

Das BM, Gogoi SB (2015b) Adsorption study of a natural product into the oil producing porous media of upper Assam Basin. Int J Res Eng Appl Sci 5(6):20-30

Elraies KA, Tan IM (2012) The application of a new polymeric surfactant for chemical EOR. In: Introduction to enhanced oil recovery (EOR) processes and bioremediation of oil-contaminated sites. Shanghai, China, p 56

Erincik MZ, Qi P, Balhoff MT et al (2018) New method to reduce residual oil saturation by polymer flooding. SPE J. 23:1-944

Fan JC, Wang FC, Chen J et al (2018) Molecular mechanism of viscoelastic polymer enhanced oil recovery in nanopores. R Soc Open Sci 5:180076

Fritz W, Schlunder EU (1981) Competitive adsorption of two dissolved organics onto activated carbon-I. Chem Eng Sci 36:721-730

Gogoi SB (2007) Flow through porous media with special reference to Enhanced Oil Recovery of Oil India Ltd. Duliajan PhD Thesis, Dibrugarh University

Gogoi SB (2010) Characterization of vesicle for enhanced oil recovery. Indian J Chem Technol 17:282-290

Gogoi SB (2011) Adsorption-desorption of surfactant for enhanced oil recovery. Transp Porous Med 90(2):589-604

Gogoi SB (2014) Effluent as surfactant for enhanced oil recovery. J Innov Energy Policies 3(1):40-50

Gogoi SB, Das BM (2012) Use of an effluent for enhanced oil recovery. Indian J Chem Technol 19:366-370
Gogoi SB, Gogoi KD (2005) Emulsion flow in bhogpara core sample with emphasis on enhanced oil recovery. Indian J Petrol Geol 14(2):55-57

Gogoi SB, Kakoty M (2017) A study of $\mathrm{CO}_{2}$ flooding on wave velocities in the Naharkatiya oil reservoir of upper Assam basin. Resour Effic Technol 3(1):101-112

Hanna H, Somasundaran P (1977) Physico-chemical aspects of adsorption at solid/liquid interfaces. II. In: Mahogany sulfonate/ berea sandstone, kaolinite. Academic Press, New York

Hawkins BF, Taylor KC, Nasr-El-Din HA (1994) Mechanisms of surfactant and polymer enhanced alkaline flooding: application to the David Lloydminster and Wainwright Sparky fields. J Can Petrol Technol 33:52-63

Hazarika K, Gogoi SB (2014) Comparative study of an enhanced oil recovery process with various chemicals for Nahorkatiya oil field. Int J Appl Sci Biotechnol 2(4):432-436

Hazarika K, Yadav R, Gogoi SB et al (2018) Characterization of crude oil for enhanced oil recovery: a study with anionic surfactant. Int J Ambient Energy 39(2):1-12

Healy RN, Reed RL (1974) Physsicochemical aspects of microemulsion flooding. Soc Petrol Eng J 14:491-501

Healy RN, Reed RL (1977) Improved oil recovery by surfactant and polymer flooding. Soc Petrol Eng J 17:129, 383. Academic Press, New York

Healy RN et al (1976) Multiphase microemulsion systems. Soc Petrol Eng J 16:147-160

Hirasaki GJ (1981) Application of the theory of multicomponent. multiphase displacement to three-component, two-phase surfactant flooding. SPE J 21:191-204

Housaindokht MR, Nakhaei A (2012) Pour, study the effect of HLB of surfactant on particle size distribution of hematite nanoparticles prepared via the reverse micro emulsion. Solid State Sci 14(5):622-625

Huh C (1979) Interfacial tensions and solubilizing ability of a microemulsion phase that coexists with oil and brine. J Colloid Interface Sci 71(2):408-426

Hunter RJ (1981) Charge and potential distribution at interfaces. In: Zeta potential in colloid science, chapter 2. Academic Press, pp $11-58$

Kim IB, Allee GL (2001) Effect of carbohydrate sources in phase $\mathrm{i}$ and phase ii pig starter diets. Asian-Australas J Anim Sci 14(10):1419-1424

Parks GA, Bruyn PL (1962) The zero point of charge of oxides. J Phys Chem 66:967-973

Vik B, Kedir A, Kippe V, et al. (2018) Viscous oil recovery by polymer injection; impact of in situ polymer rheology on water front stabilization. In Proceedings of the SPE Europec featured at 80th EAGE conference and exhibition, Copenhagen, Denmark, 11-14 June 2018

Laishun S (2000) An approach to the flam retardation and smoke suppression of ethylenevinyl acetate copolymer by plasma grafting of acrylamide. React Funct Polym 45:85-93

Laura L, Wesson J, Harwell H (2000) Surfactant adsorption in porous media. Cambridge University Press, Cambridge

Marszall L (1977) Bancroft's rule and emulsion inversion. J Colloids Interface Sci 61(1):202-203

Nasr-El-Din HA, Taylor K (1993) Interfacial tension of crude oil/alkali systems in the presence of partially hydrolyzed polyacrylamide. Colloids Surf 49:273-279

Nasr-El-Din HA, Taylor KC (1998) The role of surfactants in enhanced oil recovery. In: Shah DO (eds) Micelles, microemuslions and monolayers: science and technology, Chapter 11, pp 249-287

Nasr-El-Din HA et al (1992) Recovery of residual oil using the alkali/ surfactant/polymer process: effect of alkali concentration. J Petrol Sci Eng 6:381-401 
Phukan R, Gogoi SB, Tiwari P (2018) Enhanced oil recovery by alkaline-surfactant-alternated-gas $/ \mathrm{CO}_{2}$ flooding. J Petrol Explor Prod Technol 9:247-260

Pope GA (1980) The application of fractional flow theory to enhanced oil recovery. SPE J 20:191-205

Pope GA, Lake LW, Helfferich FG (1978) Cation exchange in chemical flooding: Part 1-Basic theory without dispersion. SPE J 18(6):418-434

Samanta A, Bera A, Ojha K, Mandal A (2012) Comparative studies on enhanced oil recovery by alkali-surfactant and polymer flooding. J Pet Explor Prod Technol 2(2):67-74

Sarmah S, Gogoi SB, Barman J, et al (2017) Study on the effects of the rheological properties for flow behaviour of assam crude oil with various chemicals. In: Proceedings of the 1st GeoMEast international congress and exhibition, Egypt 2017 on sustainable civil infrastructures, pp 148-168

Schramm LL (2000) Surfactants: fundamentals and applications in petroleum industry. Petroleum Recovery Institute, Calgary

Sheng J (2010) Modern chemical enhanced oil recovery: theory and practice. Gulf Professional Publishing, Texas, USA

Shukla A, Rehage H (2008) Zeta potentials and debye screening lengths of aqueous, viscoelastic surfactant solutions (cetyltri methyl ammonium bromide/sodium salicylate system). Langmuir 24(16):8507-8513
Soo H, Radke CJ (1984) Velocity effects in emulsion flow through porous media. Interface Sci 102(2):462-476

Torrealba VA, Johns RT (2017) Coupled interfacial tension and phase behavior model based on micellar curvatures. Langmuir 33(47):13604-13614

Torrealba VA, et al (2018a) Curvature-based equation of state for microemulsion-phase behavior. SPE J 24(2):1-13

Torrealba VA et al (2018) Description of micellar radii for phase behavior and viscosity modeling of aqueous surfactant solutions and microemulsions. Langmuir 34(50):15327-15334

Uren LC, Fahmy EH (1927) Factors influencing the recovery of petroleum from unconsolidated sands by waterflooding. Trans AIME 77:318-335

Wagner OR, Leach RO (1966) Effect of interfacial tension on displacement efficiency. Soc Petrol Eng J 6(4):335-344

Yuan Y, Lee TR, Bracco G (2013) Surface science techniques. In: Springer series in surface sciences, vol 51. Springer, Berlin

Publisher's Note Springer Nature remains neutral with regard to jurisdictional claims in published maps and institutional affiliations. 